\title{
Research Progress of Metal Fuel Motor Technology
}

\section{WANG Jin-yun ${ }^{1 *}$ ZHOU Hui-jie ${ }^{2}$ and Mao Xiao-yan ${ }^{2}$}

${ }^{1}$ Hebei Key Laboratory of Dual Medium Power Technology, Hebei Hanguang Industry Co. Ltd., China

${ }^{2}$ College of Science and Technology, Ningbo University, China

\begin{abstract}
Nano metal powder is a promising new type of fuel because it can replace the traditional non renewable energy, and could be the subject of tremendous practical and research interest for future land and water transportation. In this study, the energy performance of several typical metal fuels were compared and analyzed, and the results show that the energy density of aluminum based metal fuel is as high as $40.91 \mathrm{MJ} \times 103 \bullet \mathrm{m}-3$, the combustion heat value of reaction between iron powder and oxygen is as high as $58.14 \mathrm{MJ} / \mathrm{L}$. In addition, the research progress of metal fuel (nano Al, Fe powder) motor technology at home and abroad was summarized, and the results show that the specific impulse of nano aluminum based water reactive metal fuel engine can reach $4900 \mathrm{~N} \bullet \mathrm{s} / \mathrm{kg}$, and that of nano iron based oxygen reaction metal fuel engine can reach $3500 \mathrm{~N} \bullet \mathrm{s} / \mathrm{kg}$ when the combustion chamber pressure and temperature are $5 \mathrm{MPa}$ and $3800 \mathrm{~K}$, respectively. This will provide a reference for promoting the innovation of new energy science and technology.
\end{abstract}

\section{Keywords}

Metal fuel technology, Metal fuel engine, Nano metal fuel, Combustion mechanism, Research progress

\section{Introduction}

With the problem of energy shortage and environmental pollution becoming more and more serious in the world, many countries are trying to study green and recyclable new energy. Metal fuel [1-5] (such as aluminum, magnesium, iron, boron, beryllium, and lithium) is one of the new energy sources to replace the traditional fuel, which can significantly increase the energy and density of the power system of the land and water transportation vehicle, and greatly improve the working efficiency of the underwater operation platform. Moreover, the energy density of this new metal fuel is much higher than that of coal, oil, natural gas and other petrochemical fuels, and it does not release sulfur oxides, nitrogen oxides and other harmful gases in the combustion process. Therefore, it has a bright future as a non renewable energy substitute. Aluminum magnesium based metal fuel can react violently with water (gaseous water as oxidant) under certain conditions (high temperature and high

*Corresponding author: Dr. Jinyun Wang, Hebei Key Laboratory of Dual Medium Power Technology, Hebei Hanguang Industry Co. Ltd., Hebei, 056017, China, Tel: +86-13503102573

Accepted: July 29, 2020; Published: July 31, 2020

Copyright: ( 2020 Jin-yun W, et al. This is an open-access article distributed under the terms of the Creative Commons Attribution License, which permits unrestricted use, distribution, and reproduction in any medium, provided the original author and source are credited.

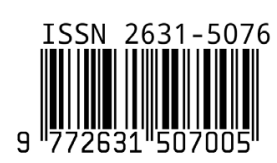
Jin-yun et al. Int J Metall Met Phys 2020, 5:056 
pressure), and releases a large amount of energy. The energy density (taking aluminum water reaction metal fuel as an example) is 4-6 times of that of fuel oil, and there is no waste gas pollution, which can make up for the shortage of current energy and has a broad application prospect [6-10].

Nano metal fuel can replace the fossil non renewable energy such as coal, oil, natural gas in the future because it has many advantages, such as high combustion calorific value, high specific energy, and high combustion rate. They would be widely used in underwater vehicles, surface ships, space vehicles, deep space detectors, deep-sea workstations, underwater drilling platforms, space as well as the power generation system of remote mountainous area. They are a new fuel with great development prospect, and become a research focus in recent years.

In recent years, metal fuel is widely used in military and civil fields because of its advantages of no pollution, high specific energy, energy saving and environmental protection. Metal fuel cell uses high energy density $\mathrm{Al}, \mathrm{Mg}, \mathrm{Zn}$ and other alloys as fuel, directly transforms the chemical energy contained in the metal into electrical energy, and provides continuous power through direct supplement or replacement of metal fuel, which has extremely important economic and social benefits to solve the problem of global oil resource shortage and urban environmental pollution. As an energy carrier, metal fuel can solve the problem of large-scale power storage over $100 \mathrm{MW}$ [11].

In the 1970s, the former Soviet Union first developed the water reaction engine technology of magnesium based fuel for the "storm" supercavitation torpedo, and the speed of torpedo had been improved revolutionarily, breaking through $200 \mathrm{kn}$. In the 1990s, the United States developed a metal fuel thermal power torpedo weapon based on metal $\mathrm{Li} / \mathrm{SF}_{6}$, which doubled its range and speed.

In recent years, Dave beech, a researcher at Oak Ridge National Laboratory in Tennessee, carried out research on nano iron powder metal fuel technology. It was found that the nano fuel made of metal materials such as iron, aluminum and boron became extremely active, and the ignition temperature was low, and a large amount of energy was released. If the engine of the car was modified, the driving distance of the car with a full tank of metal powder fuel would be three times that of the ordinary fuel.

Metal fuel would be widely used in the energy power system of various vehicles because of its special chemical properties. Some active metals such as $\mathrm{Al}, \mathrm{Mg}, \mathrm{Fe}$, and $\mathrm{B}$ were typically employed as fuel of metal fuel engine, and the water or air was used as oxidant, and these adopts special energetic materials and preparation process. These active metals take place violent reactions with water under certain conditions and convert the chemical energy of metal fuel into the kinetic energy of the vehicle. Metal fuel engine generally includes water reaction and oxygen reaction, and water reaction metal fuel engine is suitable for underwater weapons and underwater operation platform, and oxygen reaction metal fuel engine is suitable for aviation and aerospace fields and can replace conventional solid rocket propellant.

Water reactive metal fuel engine uses active metal as fuel and water as oxidant to produce violent chemical reaction in combustion chamber. The huge heat energy generated can be used as propulsion power of the vehicle. When the supercavitating vehicle sail at high speed underwater, the decelerating and expanding device can convert the dynamic pressure of high-speed seawater into high static pressure and directly inject it into the combustion chamber to burn with metal fuel, so it is also called water ramjet.

As another form of water reactive metal fuel, ALICE-SRM [12] can be used in Mars landing, deep space control survey, space exploration and other activities. In the future, an intelligent and unmanned weapon will flood land, sea, air and space, especially the application of unmanned underwater weapons will change the future combat mode. Metal fuel is of great research value as a new high-energy power of unmanned combat weapons in the future.

Specially, nano aluminum metal powder can be used as the high energy power of underwater vehicles because of its high combustion heat value, high reaction activity, storage safety. Table 1 shows the characteristics of water reactive metal fuel and oxide. According to theoretical calculation, the energy density of aluminum based metal fuel is as high as $40.91 \mathrm{MJ} \times 10^{3} \cdot \mathrm{m}^{-3}$, while that of magnesium powder fuel is only $23.21 \mathrm{MJ} \times 10^{3} \cdot \mathrm{m}^{-3}$. The 
Table 1: Characteristics of metal fuels and oxides in water reaction.

\begin{tabular}{|c|c|c|c|c|c|c|c|c|}
\hline \multicolumn{6}{|c|}{ Metal fuel } & \multicolumn{3}{|c|}{ Metallic oxide } \\
\hline $\mathbf{N}$ & $\rho / \mathrm{g} \cdot \mathrm{cm}^{-3}$ & MP/K & $\mathrm{BP} / \mathrm{K}$ & MCV/MJ.kg ${ }^{-1}$ & $\mathrm{VCV} / \mathrm{MJ} \cdot \mathrm{m}^{-3}$ & $\mathbf{N}$ & MP/K & $\mathrm{BP} / \mathrm{K}$ \\
\hline Al & 2.70 & 933 & 2767 & 15.15 & $40.91 \times 10^{3}$ & $\mathrm{Al}_{2} \mathrm{O}_{3}$ & 2315 & $3250-3280$ \\
\hline $\mathrm{Mg}$ & 1.74 & 923 & 1366 & 13.34 & $23.21 \times 10^{3}$ & $\mathrm{MgO}$ & 3098 & 3850 \\
\hline B & 2.34 & 2450 & 3931 & 18.81 & $44.02 \times 10^{3}$ & $\mathrm{~B}_{2} \mathrm{O}_{3}$ & 723 & 2320 \\
\hline $\mathrm{Be}$ & 1.85 & 1560 & 2744 & 36.03 & $66.67 \times 10^{3}$ & $\mathrm{BeO}$ & 2720 & $3000-4170$ \\
\hline $\mathrm{Li}$ & 0.53 & 454 & 1620 & 28.61 & $15.16 \times 10^{3}$ & $\mathrm{Li}_{2} \mathrm{O}$ & 1843 & 2836 \\
\hline
\end{tabular}

Note: N: Name; MW: Molecular Weight; $\rho$ : Density; MP: Melting Point; BP: Boiling Point; MCV: Mass Calorific Value; VCV: Volumetric Calorific Value.

mass and volume combustion calorific value of $\mathrm{Be}$ in water reactive metal fuel are $36.03 \mathrm{MJ} \cdot \mathrm{kg}^{-1}$ and $66.67 \times 10^{3} \mathrm{MJ} \cdot \mathrm{m}^{-3}$, respectively, but its combustion product BeO possesses great toxicity, which limits its application. metal $\mathrm{Li}$ and water are easy to start, but their unit volume energy density is low. Metal B has high energy density, but its continuous combustion performance is weak, and the oxygen consumption is high, and the price is expensive. Metal Mg powder and water are easy to start, but the volume energy density is low. Metal Al powder has high combustion heat value, and can be used as the first choice of underwater propellant. Especially, nano aluminum powder metal fuel is the best choice with the development of nano powder preparation technology.

The calculation and analysis of the calorific value of metallic fuel show that the nano-aluminum-based fuel for water reaction has a higher calorific value and is most suitable for the high-speed propulsion system of underwater vehicle, the nano-iron-based fuel for oxygen reaction has a higher specific energy density and a lower ignition temperature, good combustion stability and can be used in spacecraft power plant. In recent years, a dual-medium vehicle technology has been developed, which can not only fly at supersonic speed in the air, but also propel at super-high speed underwater.

Therefore, in this study, the research progress of water and oxygen reactive metal fuel engines at home and abroad was reviewed, the key technologies of water-reactive aluminum, magnesium-based metal fuel and nano-iron-based fuel engine (including propellant formulation, preparation, combustion chamber design, water supply flow control, steady combustion, nozzle two-phase flow characteristics, and thrust test) were discussed, the research can provide a reference for the optimization design of the dual-medium vehicle engine in the future.

\section{Research Progress of Metal Fuel Engine Technology}

Current research results show that that the study of water reaction metal fuel engine mainly focuses on the preparation of metal fuel propellant (such as aluminum, magnesium, and aluminum-magnesium alloy), combustion stability, water inlet system design, combustion chamber design, internal flow field characteristics analysis, ground ignition test, and engine thrust test. Although there are magnesium based metal fuel engines installed in the "storm" supercavitating torpedoes in Russia, according to the existing literature, most of the foreign engine technologies focus on the combustion stability of metal fuel propellants. Domestic institutions are mainly engaged in aluminum-and magnesium-based fuel performance, optimization design of engine combustion chamber and ground ignition experiments, there is no relevant report on the combustion and thrust test of the engine in the complicated underwater environment.

\section{Aluminium magnesium based water reaction metal fuel engine technology}

It was reported that on August 12, 2000, the nuclear submarine Kursk belonging to the Northern Fleet of Russia suddenly sank in the sea bottom of a certain sea area in Barents, the Arctic Ocean, about $108 \mathrm{~m}$ deep. Since then, the relevant information about the Russian supercavitation storm torpedo has been known by the world. The Russian torpedo power system just used the magnesium based water reaction metal fuel engine technology. From then on, the researchers of China's universities and scientific research institutes were very interested in the technology of metal fuel engine, and 


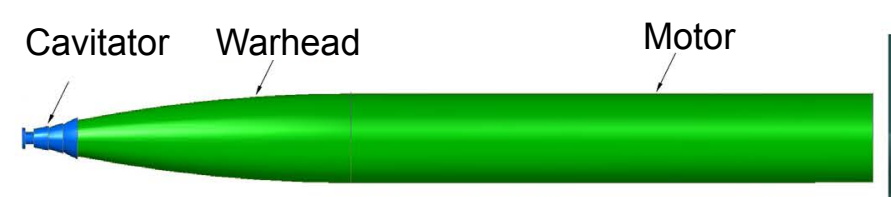

a)

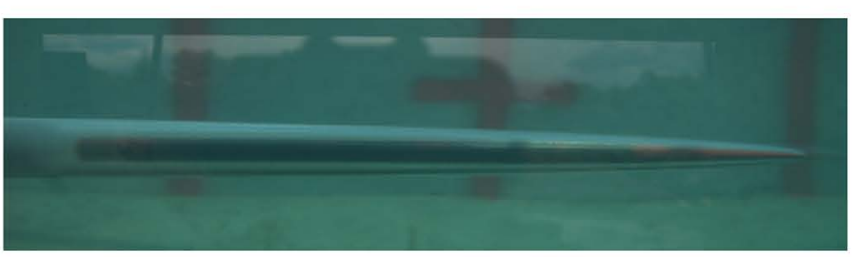

b)

Figure 1: Supercavity projectile: a) Schematic diagram of supercavitation; b) Underwater supercavitation experiment.

had carried out extensive research. For example, the principle analysis, thermodynamics simulation, preparation of metal fuel propellant formulation, design of engine combustion chamber, and ground ignition test of engine in water reactive metal fuel engine were studied by National Defense University of Science and Technology, Northwest Polytechnic University, Harbin Engineering University, Aerospace Academy, Beijing University of Technology, Xi'an Jiaotong University, and Zhejiang University. Specially, the $80 \mathrm{~mm}$ aluminum based metal fuel engine supercavitation projectile jointly developed by Harbin Engineering University and Hebei Key Laboratory of dual medium power technology has a speed of $286 \mathrm{kn}$ (as shown in Figure 1).

In China, the research of water ramjet technology started relatively late. It entered the substantial research stage since 2000, and more work mainly focused on the working principle exploration and theoretical demonstration of water reaction metal fuel engine, the calculation of propellant performance thermodynamics, engine performance analysis, metal fuel propellant preparation and performance analysis, metal fuel combustion characteristics analysis and experimental research, engine system experiment and other aspects.

$\mathrm{Hu}$, et al. [13] calculated the specific impulse performance of aluminum and magnesium based water reactive metal fuel, estimated the burning time of metal particles, and determined the design length of combustor. In addition, $\mathrm{Hu}$, et al. [14] established a one-dimensional two-phase multi-component reaction flow calculation model and a magnesium water chemical reaction kinetic model, and carried out a numerical simulation of the one-dimensional flow field of the engine. In [15], an experimental research on four kinds of water reaction metal fuel engine configurations was conducted. Through the analysis of performance parameters such as combustion chamber pressure, combustion efficiency and injection efficiency, it was found that the working process of the engine has a greater dependence on its configuration.

Yang, et al. [16] theoretically analyzed the thermal and dynamic properties of $\mathrm{Mg}$ based water ramjet. Han, et al. [17] studied the influence of the primary water inlet angle on the specific impulse performance of the secondary water inlet engine, established the two-phase flow reaction model of the engine afterburner, and carried out numerical simulation and ground direct connection experiment. The results demonstrate that when the angle of primary water inlet is about 40 , the specific impulse performance of secondary water inlet ramjet is the best.

In addition, Li [18] developed the primary combustion performance and its regulation method of high metal content magnesium based water reactive metal fuel. Based on theoretical analysis, numerical simulation and experimental investigation, the thermal decomposition performance, static and dynamic combustion performance of magnesium based water reactive metal fuel were tested. The influence of propellant formulation parameters on the thermal decomposition performance, primary combustion characteristics and combustion wave structure of magnesium based fuel was analyzed.

Wang, et al. [19] established the two-phase flow control model of engine nozzle for the optimization design of high metal content (more than $80 \%$ ) water reactive nano aluminum based metal fuel engine, carried out the two-phase flow numerical simulation based on the Runge Kutta Kiel method, and studied the combustion and flow characteristics of particles in the combustion chamber and nozzle under the spherical particle assumption model. Based on the experimental results, the theoretical results are further verified. The results show that 


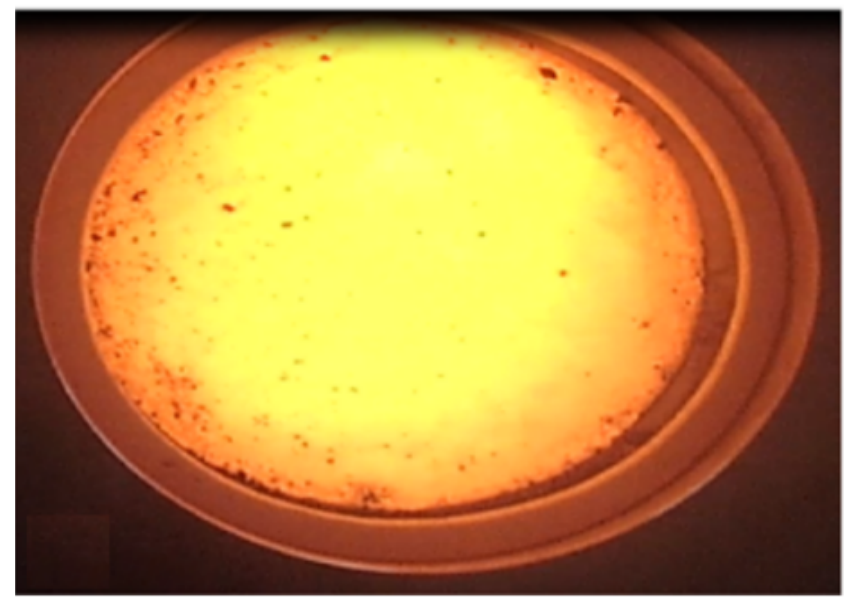

(a)

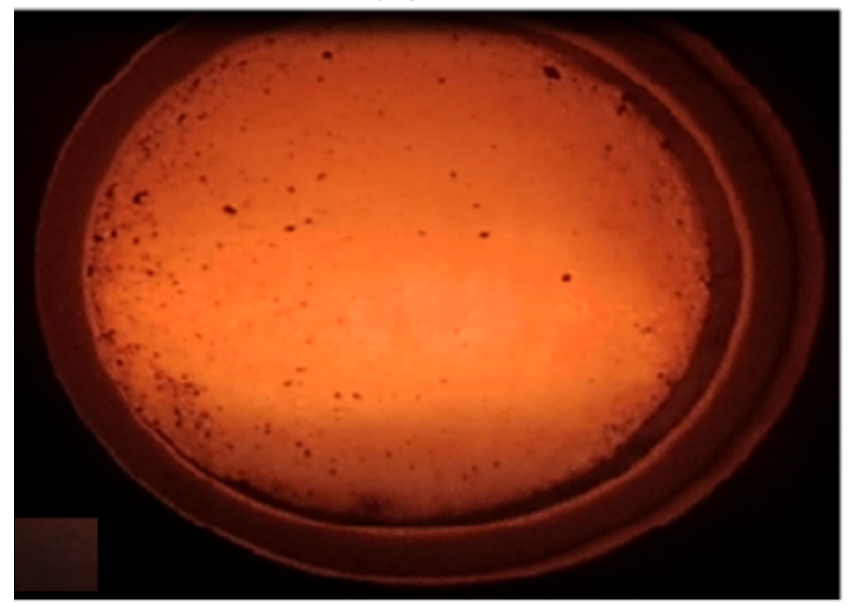

(c)

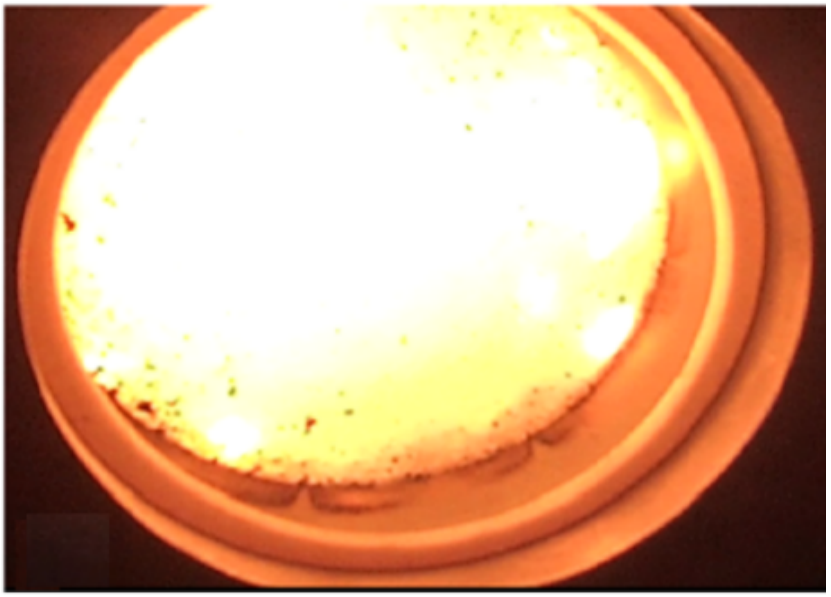

(b)

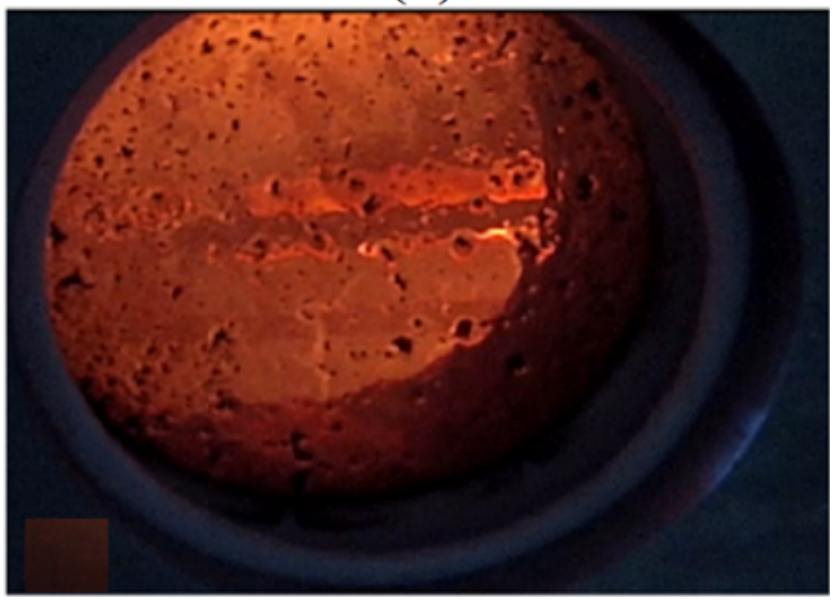

(d)

Figure 2: Aluminum hydro-reactive combustion rate testing effect.

the specific impulse of nano aluminum based water reactive metal fuel engine can reach $4900 \mathrm{~N} \cdot \mathrm{s} / \mathrm{kg}$. Aluminum hydro-reactive combustion rate testing effect is shown in Figure 2.

Figure 2 shows the test results for the burning rate of aluminum powder grain. Figure 2a shows that at the initial stage of combustion, as the temperature and pressure in the combustor do not meet the necessary conditions for full combustion, the combustion of aluminum powder begins, the temperature and pressure in the combustor gradually increase and the degree of combustion is weak. From Figure $2 \mathrm{~b}$, we can directly observe that the combustion is intense and the flame color is bright due to the increase of chamber temperature, pressure and oxygen concentration. The combustion chamber temperature reaches $3800 \mathrm{~K}$ and the pressure reaches $5 \mathrm{MPa}$. Figure $2 \mathrm{c}$ and Figure $2 \mathrm{~d}$ show that at the end of combustion, due to insuf- ficient fuel, the combustion begins to fade and the flame color gradually darkens.

As early as 2008, NASA's Phoenix Mars probe discovered the existence of solid water on Mars, and in 2019, Italian scientists announced the discovery of liquid water lake on Mars, which provided a new opportunity for the research of aluminum water/ice metal fuel engine. Metal fuel and solid water as propellants can be used as energy power for future Mars exploration, space operations and launch vehicles.

At present, foreign metal fuel engine technology, except the known Russian "storm" torpedo uses magnesium based fuel (as shown in Figure 3), other countries have not seen relevant reports. From the public information, most of them were in the stage of metal fuel combustion mechanism analysis and engine prototype test. For example, the "storm" torpedo power plant uses magnesium powder as 


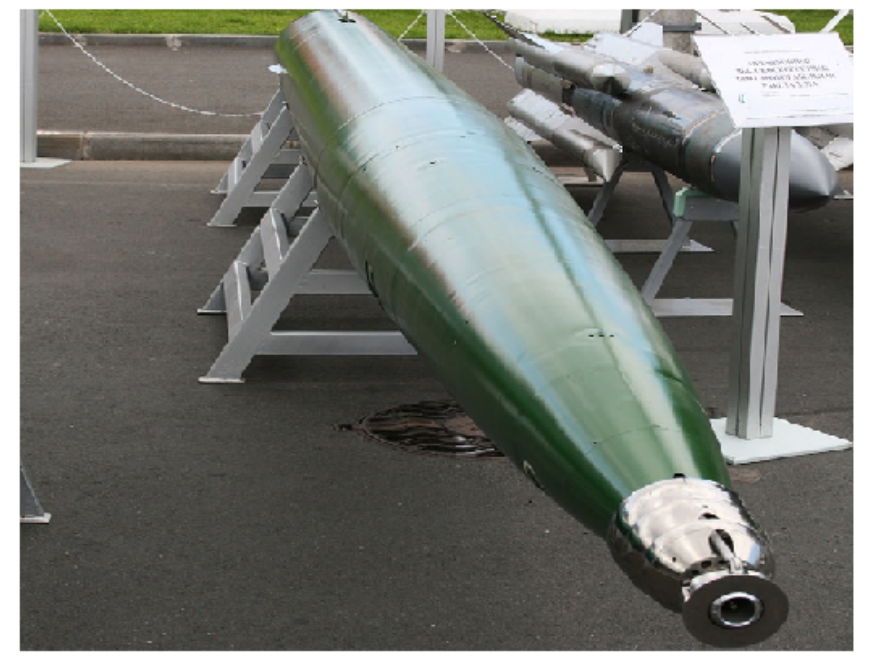

a)

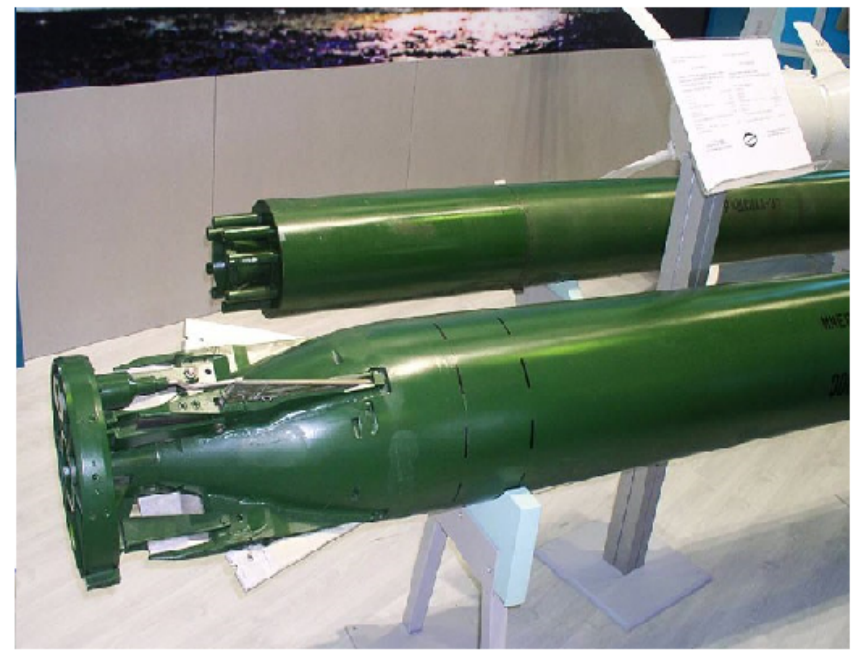

b)

Figure 3: Russian "Storm" torpedo: a) Torpedo head cavitator; b) Torpedo tail engine.

fuel and the seawater introduced into the outside as oxidant. Compared with the conventional solid rocket propellant, it does not need to carry additional oxidant, so it can save the storage space to the maximum extent and can carry a large amount of fuel, thus it has a high energy density and speed. Based on the way of high pressure carrier gas feeding, ARL, University of Pennsylvania, USA, studied the performance of $\mathrm{Al} / \mathrm{H}_{2} \mathrm{O}$ and $\mathrm{Mg} / \mathrm{H}_{2} \mathrm{O}$ system [20-22], and successfully carried out the engine prototype test.

Risha, et al. [23] studied the characteristics of nano aluminum based and boron based solid fuel in hybrid rocket engine, determined the thrust and combustion characteristics of various solid fuel formulations containing nano particle HTPB by experimental method. In this paper, 19 kinds of solid combustion formulations were studied, 17 of which contained $13 \%$ additive, the other contained $6.5 \%$ and $5.65 \%$ boron metal powder, nano aluminum powder mixed with HTPB binder and other solid fuels, and fully combusted with oxygen in the combustion chamber of LGCP hybrid rocket engine. The experimental results show that nano aluminum particles can significantly improve engine performance due to their short ignition time ( $4 \mathrm{~ns}$ ), combustion time ( $50 \mathrm{~ns}$ ) and high thermal energy.

Kalpakli, et al. [24] established an improved combustion model of boron particles in the combustion chamber of solid rocket ramjet based on computational fluid dynamics (CFD). In the model, the gasphase reaction, melting, solidification, evaporation, boiling and other phase transformation processes on the surface of boron particles were fully considered. The results show that the improved model is in good agreement with the experimental results, which can provide theoretical guidance for the design of SRM combustion chamber in the future.

King [25] developed a mathematical model to predict the aluminum particle size, oxidation cap size, shape and combustion time in the aluminum particle tracking flow tube of solid rocket motor. Based on the previous calculation results, the assumed flame structure and quasi stable model were used to predict the instantaneous aluminum particle size and oxide content. The results show that there is a good consistency between the experimental results and the predicted values of the model.

Elbasuney, et al. [26] studied the effect of different content of potassium perchlorate (KP), ammonium perchlorate (AP) oxidant and metal fuel ratio on the performance of modified double base propellant (MDB). Based on the small-scale trajectory estimation test engine, simulated the real full-scale engine condition, estimated the engine combustion rate and characteristic exhaust speed. The results show that KP can effectively improve the burning rate of propellant, AP can effectively improve the characteristic exhaust velocity of engine, aluminum powder can effectively increase the temperature of combustion chamber, improve the thermal conductivity of propellant, and improve the specific impulse of engine. 
Due to the natural advantages of aluminum based fuel, it has been widely used in recent years [27-30], especially the research on nano aluminum based fuel has been widely concerned [31-33]. For example, Wang, et al. established the combustion model of non-spherical nano aluminum powder, analyzed the unsteady combustion mechanism theoretically, and further verified the correctness of the theoretical hypothesis based on the experimental method. In [34-36], the combustion mechanism of aluminum nanoparticles was explored based on molecular dynamics simulation. Poryazov, et al. [37] performed a numerical simulation of combustion of a metallized composite solid propellant with additives of micron-and nanosized aluminum particles. In [38], some aspects of coupling between aluminum droplet combustion and inherent instability in solid rocket motor were proposed. In [39], Kalal, et al. studied the thereto-physical properties aspects on incorporation of RDX by partial replacement of AP in low aluminized propellant.

It is generally believed that the ignition of micron aluminum powder is controlled by diffusion, while the combustion of Nano aluminum powder is controlled by chemical kinetics. In order to better study the complex chemical reaction in the combustion process of nano-aluminum particles, the combustion reaction mechanism, combustion reaction speed and its influencing factors were studied based on the theory of combustion dynamics.

In order to solve the problem of metal particle combustion, many scholars have established various mathematical models under different exper- imental environments to study the combustion mechanism and characteristics of metal fuel, and the influence of experimental conditions on the ignition performance of metal particle, it lays a theoretical foundation for further research on steady state combustion of metal combustion engine. The oxidation of nano-aluminum particles follows the diffusion oxidation mechanism (DOM) and the melt dispersion mechanism (MDM), in which diffusion oxidation is suitable for slow heating rate conditions and aluminum and oxygen are diffused through the oxide shell layer. The mechanism of melt dispersion is suitable for higher heating rate. The melting of core aluminum causes the shell cracking and the core aluminum is dispersed into smaller aluminum clusters and oxidized (as shown in Figure 4). It is very important to understand the ignition and combustion mechanism of micro/Nano aluminum powder, the influence factors and the method of adjusting ignition delay time.

In summary, the foreign research on the technology of water reactive metal fuel engine mainly focuses on the combustion characteristics of metal particles (such as boron, aluminum, and magnesium, most of which are aluminum-based metal fuel propellants), the combustion mechanism of aluminum particles, the size change in the combustion process, the consumption of aluminum particles, the production of alumina, and the combustion performance of the propellants. The chemical properties of different propellants are quite different. The particle size distribution, oxidizer concentration, combustion chamber temperature and pressure have a very obvious influence on the
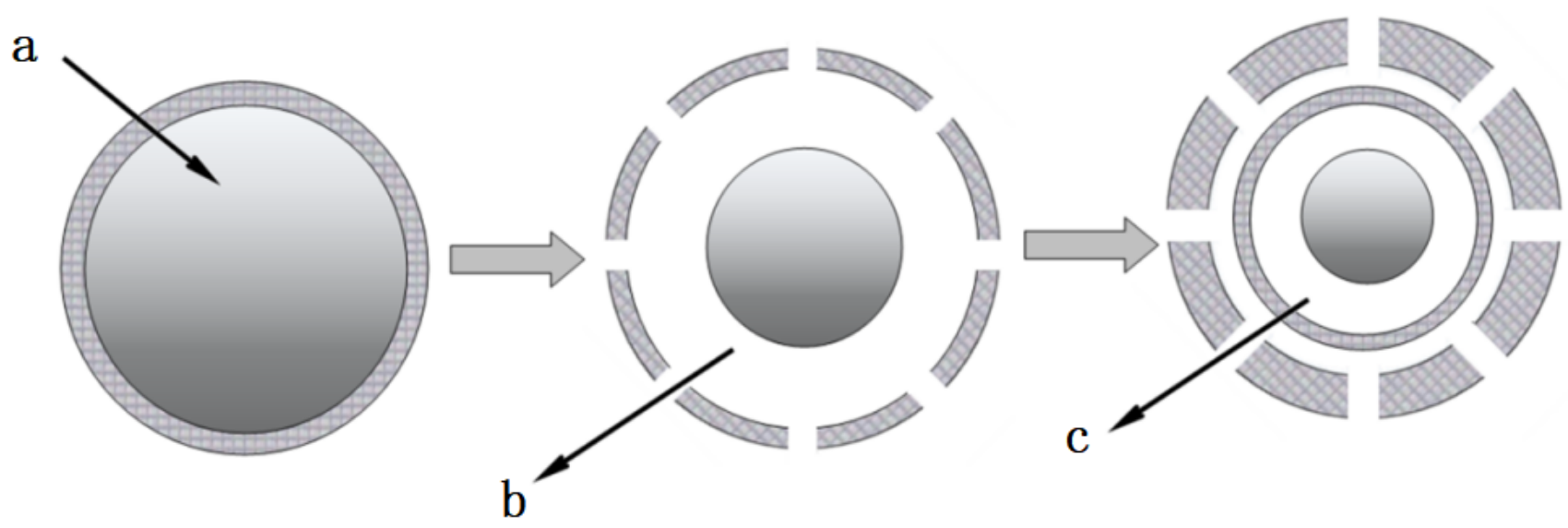

Figure 4: Melt-dispersion mechanism of nano-Al particles: a) Aluminum core covered by initial alumina shell; b) Fast melting of Al leads to spallation of the alumina shell; c) Unloading wave propagates to the center of Al molten core and generates tensile pressure which disperses small Al clusters. 
Table 2: Comparison of combustion performance between nano iron powder metal fuel and other fuels.

\begin{tabular}{|c|c|c|c|c|c|c|c|c|c|c|c|}
\hline \multicolumn{9}{|c|}{ Metal fuel } & \multicolumn{3}{|c|}{ Metallic oxide } \\
\hline \multirow[b]{2}{*}{$\mathbf{N}$} & \multirow[b]{2}{*}{ MW } & \multirow[b]{2}{*}{$\rho / \mathrm{g} \cdot \mathrm{cm}^{-3}$} & \multirow[b]{2}{*}{$\mathrm{MP} / \mathrm{K}$} & \multirow[b]{2}{*}{$\mathrm{BP} / \mathrm{K}$} & \multicolumn{2}{|c|}{ Water reaction } & \multicolumn{2}{|c|}{ Oxygen reaction } & \multirow[b]{2}{*}{1} & \multirow[b]{2}{*}{$\mathrm{MP} / \mathrm{K}$} & \multirow[b]{2}{*}{$\mathrm{BP} / \mathrm{K}$} \\
\hline & & & & & $\begin{array}{l}\mathrm{MCV} / \\
\mathrm{MJ} \cdot \mathrm{kg}^{-1}\end{array}$ & $\begin{array}{l}\mathrm{VCV} / \\
\mathrm{MJ} \cdot \mathrm{L}^{-1}\end{array}$ & $\begin{array}{l}\text { MCV/ } \\
\text { MJ } \cdot \mathrm{kg}^{-1}\end{array}$ & $\mathrm{VCV} / \mathrm{MJ} \cdot \mathrm{L}^{-1}$ & & & \\
\hline $\mathrm{Fe}$ & 55.84 & 7.86 & 1811 & 3273 & 0.902 & 7.091 & 7.397 & 58.14 & $\mathrm{Fe}_{2} \mathrm{O}_{3}$ & 1839 & - \\
\hline Al & 26.98 & 2.70 & 933 & 2767 & 15.15 & 40.91 & 31.054 & 83.85 & $\mathrm{Al}_{2} \mathrm{O}_{3}$ & 2315 & 3250 \\
\hline $\mathrm{Mg}$ & 24.30 & 1.74 & 923 & 1366 & 14.81 & 25.77 & 24.761 & 43.08 & $\mathrm{MgO}$ & 3098 & 3850 \\
\hline Li & 6.94 & 0.53 & 454 & 1620 & 28.61 & 15.16 & 42.998 & 22.79 & $\mathrm{Li}_{2} \mathrm{O}$ & 1843 & 2836 \\
\hline $\mathrm{Be}$ & 9.01 & 1.85 & 1560 & 2744 & 36.03 & 66.67 & 62.700 & 116.00 & $\mathrm{BeO}$ & 2720 & 3580 \\
\hline B & 10.81 & 2.34 & 2450 & 3931 & 18.81 & 44.02 & 267.06 & 624.94 & $\mathrm{~B}_{2} \mathrm{O}_{3}$ & 723 & 2320 \\
\hline
\end{tabular}

Note: N: Name; MW: Molecular Weight; $\rho$ : Density; MP: Melting Point; BP: Boiling Point; MCV: Mass Calorific Value; VCV: Volumetric Calorific Value.

steady combustion of propellants.

Scholars at home and abroad try to analyze the combustion process of metal fuel from the perspective of combustion mechanism. Due to the different chemical composition, the combustion process of metal fuel becomes extremely complex, including multi-phase flow combustion, turbulent combustion, unsteady combustion, phase change and other processes. According to the current research situation, the researchers explore the combustion characteristics of metal particles, such as combustion rate, particle trajectory, size change, agglomeration, fragmentation and other phenomena through a variety of observation and measurement methods. Due to the complexity and unpredictability of the combustion process of metal propellant, a unified theoretical model can not be established to explain all kinds of phenomena in the combustion process of metal fuel.

\section{Nano Fe based oxygen reactive metal fuel en- gine technology}

Due to its high activity, low ignition temperature, high combustion calorific value and no pollution of reaction products, nano metal powder fuel can be used as the energy power system of future water transportation $[40,41]$, as well as the propulsion device of automobile and space vehicle, and the energy power supply system of remote mountain areas. The outstanding advantages of nano iron powder $[42,43]$ are that the fuel can be stored safely without danger, the reaction products have no exhaust emission, the iron oxide can be reduced and reused through $\mathrm{H}_{2}$, and it can replace the existing non renewable fossil fuels such as coal, oil, and natural gas for power generation or as the energy power of automobiles, ships and aerospace in the future. It is a new fuel with great practical application value and development prospect, and has attracted much attention in recent years.

Table 2 shows the comparison of water/oxygen reaction combustion performance between nano iron powder metal fuel and other metal fuels. The calculation results show that the combustion heat value of reaction between iron powder and oxygen is as high as $58.14 \mathrm{MJ} / \mathrm{L}$, and nano Al powder has a great advantage in underwater. Although the energy density of oxygen reaction nano Al powder is higher than that of nano iron powder, the cost is expensive, and the ignition temperature (about $650^{\circ} \mathrm{C}$ ) is also high. Other metals have been compared before. In contrast, nanometer iron powder can be used as energy power fuel for aerospace engineering because of its low ignition temperature (250-280 $\left.{ }^{\circ} \mathrm{C}\right)$, fast combustion speed, reducible oxide and high volume energy density.

American researcher beach, et al. $[6,8,44,45]$ put forward an idea that it is to use nano iron powder as the fuel of automobile, the future automobile will bid farewell to the era of fuel oil. Especially, under the premise of modern society's human pursuit of livable, green, energy-saving, low-carbon and environmental protection concept of life, this idea is particularly suitable for the development of today's human society. Beach research found that the $50 \mathrm{~nm}$ powder has a high activity, the particles can be ignited at $250{ }^{\circ} \mathrm{C}$, and the temperature can reach $800{ }^{\circ} \mathrm{C}$. In addition, iron oxide particles can also be reduced to iron through hydrogen at 425 
${ }^{\circ} \mathrm{C}$. When hydrogen reacts with oxygen to produce water, the nano fuel burns again. Nano iron powder has a broad application prospect as automotive fuel, but its key technologies such as burning rate control technology, metal particle size optimization processing technology, waste collection technology, fuel delivery and so on have not been solved yet, and the design of metal fuel engine system needs to be optimized.

The research of beach, et al. theoretically demonstrated the feasibility of nano iron powder as automobile fuel [45]. Their research work mainly focused on the analysis of combustion characteristics of nano iron powder fuel. They found that 50 $\mathrm{nm}$ iron powder particles can burn at a relatively low temperature $(1000 \sim 1200 \mathrm{~K})$. The combustion products contain Fe (Ш) mixture, and iron oxide can be easily reduced to $\mathrm{Fe}$ in the temperature range of $673 \mathrm{k} \sim 773 \mathrm{~K}$ at an atmospheric pressure.

Recently, Bergthorson, et al. [46] proposed that burning metal powder directly in the air can obtain higher energy density, and the high energy heat generated by metal fuel combustion can be used as clean energy directly for Rankine and Stirling external combustion engines (ECEs), and thermal cells. The comparison between $\mathrm{Fe}, \mathrm{Al}, \mathrm{B} / \mathrm{Al}, \mathrm{Zr}$ and other metal fuel flame and methane burning flame was made (as shown in Figure 5). The results show that the combustion rate of particles is very high, and self-sustaining combustion is realized by gas molecules flowing up from the thermal reaction zone to the unburned zone. Iron powder can be used as the first choice of metal air fuel engine because of its recyclable and reusable advantages.

Based on the different oxidation environment of the improved combustion chamber, Julien, et al. [47] studied the flame structure and particle combustion characteristics of the mixture of methane and iron powder, focusing on the influence of particle combustion model on the flame structure and propagation speed in different oxidation environment. Wen, et al. [48] studied the thermal oxidation of iron nanoparticles and its effect on chemical cycle combustion by experimental method. The results show that the heat release recorded by DSC is in the range of $1.67 \sim 2.92 \mathrm{~kJ} \mathrm{~g}^{-1}$, and the activation energy of Fe nanoparticles is about $0.9 \sim 1.9 \mathrm{eV}$. In [49], the combustion characteristics of nano fuel containing boron ( $~ 80 \mathrm{~nm})$ and iron $(\sim 25 \mathrm{~nm})$ particles were studied. The results show that the liquid phase and solid phase particles coexist in the combustion process of iron powder, in the final stage of combustion, some particles formed large agglomerations.

Mandilas, et al. [50] carried out research on the oxidation and combustion characteristics of iron nanoparticles under ideal and real engine conditions, focusing on the study of Fe particles with different morphology characteristics and 25-85 nm particle size. The oxidation characteristics were studied through thermogravimetric analysis and customized impact tube, constant volume container and compression ignition $(\mathrm{Cl})$ engine configuration. The results show that although there are

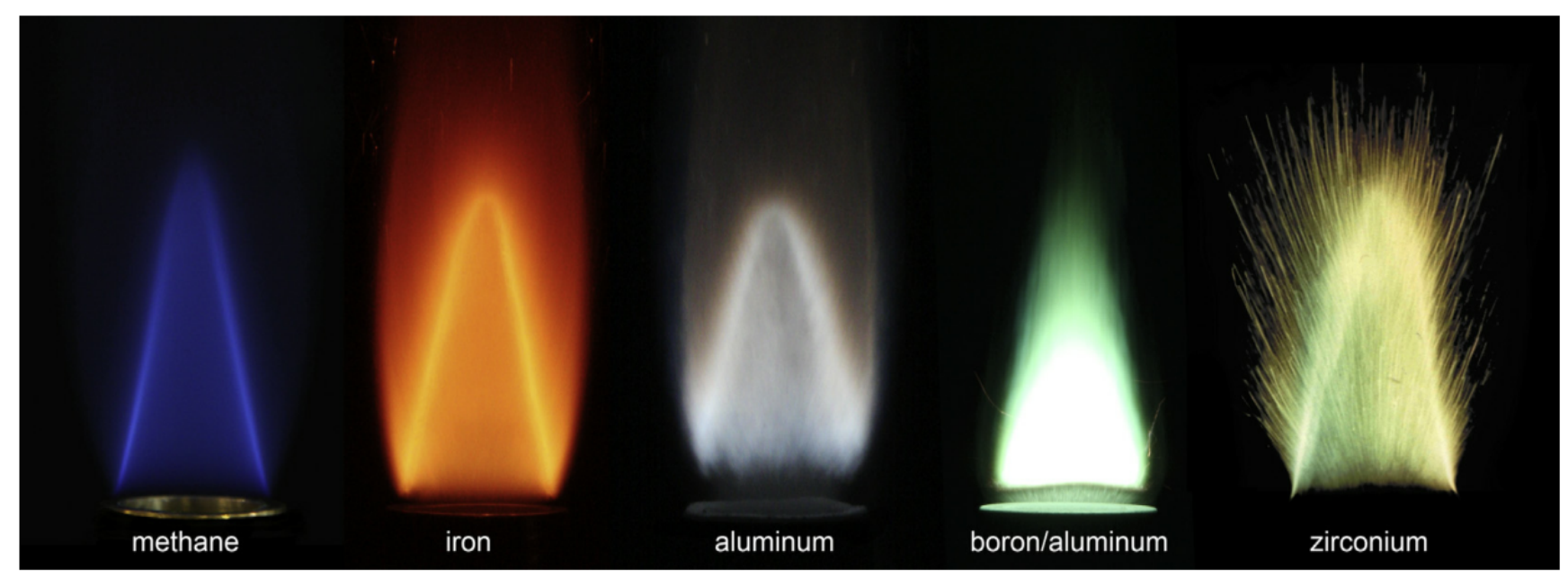

Figure 5: Stabilized flames of various metal fuels with air compared to a methane-air flame (We can see that different metal combustion presents different colors of flame. Compared with methane flame, metal fuel flame is brighter and has higher temperature). 

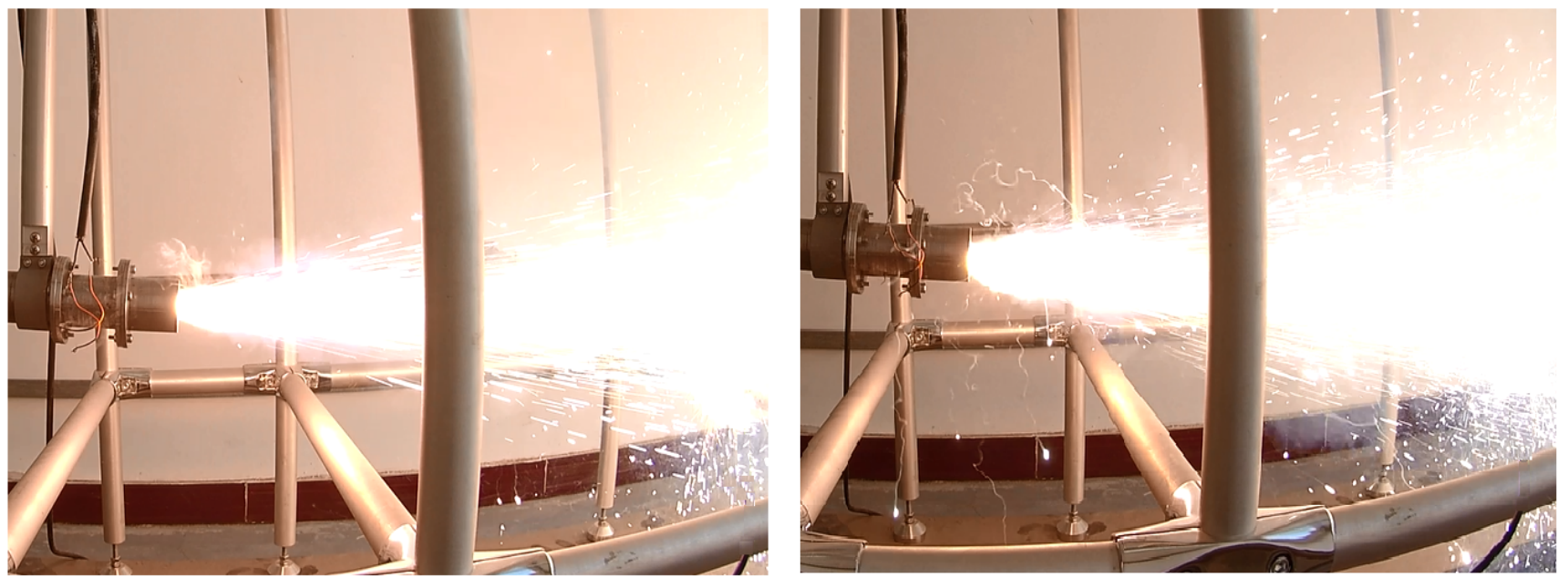

Figure 6: Experiment on nanometer iron powder fuel engine.

various technical challenges in the research work, the combustion of Fe nanoparticles in a slightly improved $\mathrm{Cl}$ engine is feasible.

Wang, et al. [40] studied the two-phase flow characteristics of the nozzle of the oxygen reaction nano iron-based metal fuel engine. The two-phase flow governing equations of the nozzle of the nano iron-based metal fuel engine were established, and the two-phase flow of the nano iron-based fuel particles was simulated, and the two-phase flow loss of the engine was evaluated. The combustion and flow characteristics of the particles in the combustion chamber and nozzle were investigated, and the influence factors of engine specific impulse performance were further studied. Finally, the rationality of the theoretical model was verified by the combustion experiment and thrust test experiment of the nano iron-based metal fuel engine.

In addition, Wang, et al. [51] studied the twophase flow characteristics of the nozzle of the metal fuel engine considering the non-spherical particles. Specially, the three particle models of spherical, ellipsoid and cubic were fully taken into account, and the particle resistance coefficient and the particle Nusselt number under different shapes and angles of attack were considered. In this study, the two-phase flow governing model of the non spherical particle nozzle was established, involving the three particle shapes. The specific impulse loss including the simulation of particle temperature lag and velocity lag under different attack angles was evaluated. Finally, the rationality of the theoretical model was further verified by the experimental method. The experiment on nanometer iron pow- der fuel engine is shown in Figure 6, and the specific impulse of nano iron based metal fuel engine can reach $3500 \mathrm{~N} \cdot \mathrm{s} / \mathrm{kg}$ when the pressure is maintained at $5 \mathrm{Mpa}$.

In summary, the domestic and foreign technical literature on metal Fe powder fuel is very limited, mainly focusing on the combustion characteristics of Fe powder, such as beach, et al., Julien, et al., Wen, et al., and Mandilas, et al. The domestic research results are mainly concentrated in the work of Yang, et al., He, et al., Gao, et al., and Wang, et al. [51-54].

At present, there are few reports on the nano Fe powder metal fuel engine technology, propellant formulation and preparation technology, and two-phase flow characteristic analysis of nozzle. Because of its special advantages, nano-Fe powder (especially for the high metal content nano-Fe powder metal fuel engine) can be used in the space high-speed propulsion system of dual medium vehicle in the future. The particle steady-state combustion technology and two-phase flow loss governing of engine nozzle are very important for the engine optimization design and engine performance improvement.

\section{Conclusions}

In this study, the latest research results of metal fuel technology were reviewed, several active metals were compared from the perspective of energy, and the research progress of water reactive metal fuel (mainly aluminum and magnesium) and oxygen reactive nano metal fuel (mainly iron powder) engine technology was reviewed. The specific 
impulse of nano aluminum based water reactive metal fuel engine can reach $4900 \mathrm{~N} \cdot \mathrm{s} / \mathrm{kg}$, and that of nano iron based oxygen reaction metal fuel engine can reach $3500 \mathrm{~N} \cdot \mathrm{s} / \mathrm{kg}$ when the pressure and temperature are $5.0 \mathrm{MPa}$ and $3800 \mathrm{~K}$, respectively. Nano metal fuel, as a new alternative to non renewable energy in the future, has absolute advantages. In the future, a kind of dual medium metal fuel engine technology will enter the field of scientific research. This technology will not only enable the vehicle to navigate at a high speed in the underwater supercavitation, but also to advance at a high speed in the water, which will greatly promote the development of national aerospace and underwater weapon equipment technology.

\section{Acknowledgments}

The authors gratefully acknowledge the partial financial support from the Science and Technology Department of Heibei Province, China (grant number 16211013D) and the Handan Science \& Technology Development Bureau (grant number 1511103015).

\section{Financial Interest}

The authors declare no competing financial interest.

\section{Foundation Item}

Science \& Department of Heibei Province (No. 16211013D), Handan Science \& Technology Development Bureau (No. 1511103015).

\section{References}

1. LB Li, X Chen, O Musa, CS Zhou, M Zhu (2018) The effect of pressure and oxygen concentration on the ignition and combustion of aluminum-magnesium fuel-rich propellant. Aerospace Science and Technology 76: 394-401.

2. M Zhu, X Chen, CS Zhou, JS Xu, O Musa, et al. (2016) Experimental and numerical investigations on the decomposition and combustion characteristics of composite propellant with $\mathrm{Mg} / \mathrm{Al}$ particles additives. Applied Thermal Engineering 111: 863-875.

3. NS Sarvestani, MHA Fard, M Tabasizadeh, H Nayebzadeh, T Chu Van, et al. (2020) Synthesize of magnetite $\mathrm{Mg}$-Fe mixed metal oxide nanocatalyst by urea-nitrate combustion method with optimal fuel ratio for reduction of emissions in diesel engines. Journal of Alloys and Compounds 838: 155627.

4. XD Meng, K Yang, MJ Zhang, F Gao, Q Wang, et al.
(2020) Experimental study on combustion behavior and fire extinguishing of lithium iron phosphate battery. Journal of Energy Storage 30: 101532.

5. J Buckmaster, TL Jackson (2014) Modelling the combustion of a sub-micron aluminium particle. Combustion Theory and Modelling 18242-18260.

6. YG Li (2011) Metal powder: Alternative zero carbon fuel. Nature \& Science Technology 01: 28-31.

7. W Zhang, WH Zhang, X Zhou (2013) Magnesium based water reactive metal fuel. National Defense Industry Press, China, 1-13.

8. S Jack (2011) Metal fuel. Resources and Human Living Environment 04: 40-41.

9. S Li, Z Lin, T Wang, Y Sun, Xu Han, et al. (2006) The effects of aluminum size on the combustion characteristics of high energy propellants with higher burning rate. 42nd AIAA/ASME/SAE/ASEE Joint Propulsion Conference \& Exhibit 2006-4930.

10.F Chong, L Shufen (2002) Experimental research of the effects of superfine aluminum powders on the combustion characteristics of NEPE propellants. Propellants Explosives Pyrotechnics 27: 34-38.

11.YG Tang (2012) New technology of metal fuel cell. Information on Functional Materials 9: 21-25.

12.PA Liu, L Wang, L Wang (2017) Numerical calculation of internal flow field of aluminum ice engine. Solid Rocket Technology 40: 425-431.

13.Hu F, Zhang WH, Xia ZX (2007) Theoretical study on specific impulse performance and combustor length design of water reactive metal fuel engine. Solid Rocket Technology 30: 12-16.

14.F Hu (2008) Theoretical analysis and experimental study of $\mathrm{Mg}$ based fuel water ramjet. Doctoral dissertation, National University of Defense Science and Technology.

15.F Hu, WH Zhang, ZY Jiang (2012) Configuration test of metal fuel / water ramjet. Propulsion Technology 33: $125-130$.

16.Y Yang, M He (2009) Theoretical investigation of thermodynamic performance for a ramjet based on a magnesium-water reaction. Engineering for the Maritime Environment 224: 61-72.

17.C Han, ZX Xia, JX Hu (2009) Study on the influence of primary water inlet angle on specific impulse performance of water ramjet. Solid Rocket Technology 32: 496-499.

18.SL Li (2009) Study on the primary combustion performance of magnesium based water reactive metal 
fuel for water ramjet. Doctoral dissertation, University of National Defense Science and Technology, 11.

19.JY Wang, ZL Yang, MJ Wang (2018) Investigation of nozzle two-phase flow characteristics for nanometer aluminum powder combustion in a metal fuel motor. Powder Technology 339: 446-458.

20.T Miller, J Herr (2004) Green rocket propulsion by reaction of $\mathrm{Al}$ and $\mathrm{Mg}$ powders and water. 40th AIAA/ ASME/SAE/ASEE Joint Propulsion Conference and Exhibit 2004-4037.

21.TF Miller, JL Walter, DH Kiely (2002) A next-generation AUV energy system based on aluminum-seawater combustion. Workshop on Autonomous Underwater Vehicles.

22.TF Miller (2002) A high-pressure, continuous-operation cyclone separator using a water-generated flow restriction. Powder Technology 122: 61-68.

23.GA Risha, BJ Evans, E Boyer, RB Wehrman, KK Kuo (2003) Nano-sized aluminum and boron-based solid-fuel characterization in a hybrid rocket engine. 39th AIAA/ASME/SAE/ASEE Joint Propulsion Conference and Exhibit 2003-4593.

24.B Kalpakli, EB Acar, A Ulas (2017) Improved combustion model of boron particles for ducted rocket combustion chambers. Combustion and Flame 179: 267-279.

25.MK King (2009) Aluminum combustion in a solid rocket motor environment. Proceedings of the Combustion Institute 32: 2107-2114.

26.S Elbasuney, A Fahd, HE Mostafa (2017) Combustion characteristics of extruded double base propellant based on ammonium perchlorate/aluminum binary mixture. Fuel 208: 296-304.

27.M Pini, G Breglia, M Venturelli, L Montorsi, M Milani, et al. (2020) Life cycle assessment of an innovative cogeneration system based on the aluminum combustion with water. Renewable Energy 154: 532-541.

28.VN Emelyanov, IV Teterina, KN Volkov (2020) Dynamics and combustion of single aluminium agglomerate in solid propellant environment. Acta Astronautics.

29.Y Feng, Z Xia, L Huang, M Likun (2018) Effect of ambient temperature on the ignition and combustion process of single aluminium particles. Energy 162: 618-629.

30.Y Dubkova, A Mostovchikov, T Kuznetsov (2018) Combustion of mixture containing the activated aluminium powder. MATEC Web of Conferences 194: 01014.

31.JY Wang, ZL Yang (2019) Theoretical study on com- bustion of non-spherical particles in nano aluminized propellant in air. Materials Research Express 6: 065064.

32.JY Wang, ZL Yang (2019) Experimental study on the effect of non-spherical particles on steady combustion in nano-aluminized propellant in air. Materials Research Express 6: 115054.

33.JY Wang, ZL Yang, MJ Wang (2020) Effect of non-spherical particles on burning behavior during aluminum combustion. Particuology 51: 173-183.

34.PA Liu, JP Liu, MJ Wang (2019) Adsorption of ethanol molecules on the Al ( $\left.\begin{array}{llll}1 & 1 & 1\end{array}\right)$ surface: A molecu-lar dynamic study. Royal Society Open Science 6: 181189.

35.JP Liu, PA Liu, MJ Wang, W Wang, Fangwei Lv, et al. (2020) Combustion of Al nanoparticles coated with ethanol/ether molecules by non-equilibrium molecular dynamics simulations. Materials Today Communications 22: 100819.

36.PA Liu, JP Liu, MJ Wang (2019) Ignition and combustion of nano-sized aluminum particles: A reactive molecular dynamics study. Combustion and Flame 201: 276-289.

37.VA Poryazov, A Yu Krainov (2018) Numerical simulation of combustion of a metallized composite solid propellant with additives of nanosized aluminum particles. Key Engineering Materials 769: 346-351.

38. Orlandi, M Plaud, F Godfroy, S Larrieu, N Cesco (2019) Aluminium droplets combustion and SRM instabilities. Acta Astronautica 158: 470-479.

39.RK Kalal, SK Jangid, H Shelchar, PS Alegaonkar, A Kumar (2020) Thermo-physical properties and combustion wave aspects of RDX contain low aluminium composite propellant. Combustion and Flame 218: 12-17.

40.JY Wang, ZL Yang, MJ Wang (2018) Numerical and experimental studies on nozzle two-phase flow characteristics of nanometer-scale iron powder metal fuel motor. Advanced Powder Technology 29: 27532764.

41.JL Sun, PA Liu, MJ Wang, J Liu (2020) Molecular dynamics simulations of melting iron nanoparticles with/without defects using a reaxff reactive force field. Scientific Reports 10: 3408.

42.S Zhang, X Wang, ZZ Mao, Y Li, B Jin, et al. (2020) Effect of calcination condition on the performance of iron ore in chemical-looping combustion. Fuel Processing Technology 203: 106395.

43.P Toth, Y Ogren, A Sepman, P Gren, H Wiinikka (2020) Combustion behavior of pulverized sponge iron as a 
recycla- ble electro-fuel, Powder Technology 373: 210-219.

44.DB Beach, BG Sumpter (2006) Running on iron: Metal nanoparticles show promise as future fuels. Oak Ridge National Laboratory Review 39: 26.

45.BG Sumpter, DB Beach, SD Labinov, RK Richards, AJ Rondinone, et al. (2007) Solid-state combustion of metallic nanoparticles: New possibilities for an alternative energy carrier. Journal of Energy Resources Technology 129: 29-32.

46.JM Bergthorson, S Goroshin, MJ Soo, P Julien, J Palecka, et al. (2015) Direct combustion of recyclable metal fuels for zero-carbon heat and power. Applied Energy 160: 368-382.

47.P Julien, S Whiteley, S Goroshin, MJ Soo, DL Frost, et al. (2015) Flame structure and particle-combustion regimes in premixed methane-iron-air suspensions. Proceedings of the Combustion Institute 35: 24312438.

48.D Wen, P Song, K Zhang, J Qian (2011) Thermal oxidation of iron nanoparticles and its implication for chemical-looping combustion. Journal of Chemical Technology and Biotechnology 86: 375-380.
49. Y Gan, YS Lim, L Qiao (2012) Combustion of nanofluid fuels with the addition of boron and iron particles at dilute and dense concentrations. Combustion and Flame 159: 1732-1740.

50.C Mandilas, G Karagiannakis, AG Konstandopoulos, C Beatrice, S Molina, et al. (2016) Study of oxidation and combustion characteristics of iron nanoparticles under idealized and enginelike conditions. Energy Fuels 30: 4318-4330.

51.WJ Wang, ZL Yang (2019) Effect of non-spherical particles on nozzle two-phase flow loss in nano-iron powder metal fuel motor. Aerospace Science and Technology 91: 372-381.

52.L Yang, YQ Zhu, ZH Wang, GJ Wang, JH Zhou, et al. (2010) Experimental study on combustion characteristics of micro nano metallic iron powder. Journal of Zhejiang University 44: 1562-1566.

53.DD He, J Jin, Y Lu, CW Cai, YN Fu, et al. (2012) Study on combustion characteristics of nanometer iron powder. Shanghai University of Technology 34: 8892.

54.WJ Gao, J Jin, WY Zeng (2013) Study on the combustion kinetics model of nanometer iron powder. Science Technology and Engineering 33: 9808-9812. 